\title{
COMMUNITY EVENTS: COMMITTEES, CHALLENGES, AND COOPERATION
}

\author{
MARJORY BREWSTER
}

Business School, Queen Margaret University, East Lothian, Edinburgh, UK

\begin{abstract}
Despite the growing interest in community-led organizations there remains some events operated by not-for-profit organizations that have not been fully explored, even when there is a significant sociocultural contribution to the host communities. Although this study is set within Highland Games there are many similarities to a variety not-for-profit event organizations managing traditional community events or cultural celebrations such as Hogmanay or Common Ridings. The challenges facing volunteer organizations are considerable when attempting to maintain cultural traditions and committee stabilization, for numerous not-for-profit event organizations. Furthermore, the organizers of community events may not be traditionally perceived as the protectors of a country's culture, there is no doubt that many events play a significant role in promoting unique elements of tradition and culture. Adopting a qualitative methodology, the article highlights some of the challenges encountered to maintain a stable support system for dedicated groups of individuals. Findings highlight the community focus and need for synergetic support systems in communities to ensure longevity of significantly important events.
\end{abstract}

Key words: Management; Community; Not-for-profit; Culture; Volunteers; Highland Games

Introduction

Community events have a significant social place in society and are recognized as unifying residents through cultural narratives. Specifically, in terms of creating social capital and engagement across a broad spectrum of stakeholders who manage and support community events. Although academics often eschew community events in favor of larger more impactful events, community events have attracted interest since the 1970s. Initially associated with native festivals and cultural tourism in the form of tourist attractions (e.g., Greenwood, 1977) it was not until the 1990s the increasing academic interest was evident within the literature (see Getz, 1991; Hinch \& Delamere, 1993). Furthermore, many small-scale sporting events lack academic rigor, although there is increasing interest at an organizational and management level (e.g., Brewster, 2014; Brewster, Connell, \& Page, 2009; Darcy, Maxwell, 
Edwards, Onyx, \& Sherker, 2014; Davies, 2015; De Bres \& Davis, 2001; Derrett, 2005; Dimmock \& Tiyce, 2001; Litvin, 2013; O’Sullivan, Pickernell, Senyard, \& Keast, 2008; Rogers \& Anastasiadou, 2011; Zakus, Skinner, \& Edwards, 2009). This study adds to the literature relating to the management of not-for-profit cultural community events. The challenges of these organizers within the community environment is explored within Highland Games; however, similar challenges are likely to be encountered by numerous types of not-for-profit community festivals such as book, craft, or traditional food festivals organized by volunteers.

As a social motivator, community events provide space for socialization and interaction of friends and family where bonhomie is particularly important to diasporic communities. Where distantly located returning friends and relatives are motivated by the event to return to childhood neighborhoods. Emanating from its Scottish Highland roots as a traditional sporting event, one of the key drivers of the presence and longevity of Highland Games overseas, and supportive presence within Scotland, is the global diaspora of Scottish migrants. Where culture and national identity are significant characteristics of constructive recognition (Brewster, 2010, 2014), enjoyed through the continuance of indigenous cultural performance and intercultural exchange (Phipps, 2010). As highlighted by Azara, Wilthsier, and Greatorex (2018), increasingly the promotion of cultural events is utilized to increase visitor numbers, which can lead to challenges associated with commercialization. Given the contribution by the Scottish diaspora to the British Imperial growth and Dominion workforce, the cultural contributions and identity that the Highland Games offer fulfil the desire to preserve Highland traditions, dress, culture, and music. There are many examples of festivals with historical cultural links to Scotland such as Burns Night (Bueltmann, 2012; Rigney, 2011), Hogmanay (Mair \& Frew, 2013), fire festivals at Hogmanay (McNeill, 1959, 1968), and Highland Games (Brander, 1992; Bueltmann, 2012; Burnett, 2000; Colquhoun \& Machell, 1927; Donaldson, 1986; McCombie Smith, 1891; Ray, 2001).

Similar to other traditional community events, where the origins are in the distant past, and have evolved as a tradition within communities, some Highland Games have centuries of history. Such festivals are significant and likely to play a prominent role in the annual events calendar of many communities. It is suggested that some culturally based events date back to the Druids such as Beltane festivals originally staged throughout Scotland to celebrate the coming of summer, or Lammas Celtic Festivals associated with harvest and Festivals of the Corn (McNeill, 1959, 1968). In Scotland, events embedded in communities are the Common Ridings in the Borders, Hogmanay Fire celebrations such as the Fireball Procession at Stonehaven or Biggar Bonfire (McNeill, 1959, 1968), and the Up Helly Aa Festival in Shetland (Finkel, 2010). There are many local festivals with unknown origins that play a central role in the annual events calendar of many communities. Elsewhere, similar events may occur, such as agricultural shows (Darian-Smith, 2011), rural Australian events (Chappel \& Loades, 2009; C. Gibson, Connell, Waitt, \& Walmsley, 2011), or the Mongolian Naadam Festival (Thompson \& Schofield, 2009).

Typically, community-centered events are primarily staged for the benefit of the residents, through the creation of an enjoyable social experience over the pursuit of financial gain. Most events are created to serve a purpose, such as generating revenue through increasing tourism and visitor numbers or to achieve societal goals and support the host community. Yet, studies of community events do not command the same level of interest favored by large events. Cultural events with sporting themes are prevalent around the world, with many evolving from traditional cultural events to spectacular festivals with touristic appeal. Particularly festivals linked to indigenous culture, such as the Dragon Boat races in China (McCartney \& Osti, 2007), the Naadam Festival in Mongolia (Schofield \& Thompson, 2007), and the Garma Festival, Northeast Arnhem Land, Australia (Phipps, 2011).

Like many community events, most Highland Games function on not-for-profit principles where success is achieved by generating enough income to finance and support the event in subsequent years. As volunteers, the organizers contribute their time, skills, and expertise on a nonremuneration basis to manage and stage the events. Archetypal of many not-for-profit community events that rely on the goodwill of residents for assistance and support, and it is the commitment of volunteers that 
sustain many events as an essential organized workforce. The nonremunerated volunteer organizers are crucial to the sustainability of community events where, unlike commercial enterprises, the voluntary sector operates for the benefit of its members over the pursuit of financial gain (Darcy et al., 2014; Green \& Jones, 2006).

Competition is key to the success of Highland Games and attracts international players to Scotland, often to compete at multiple events. The level of international competitors across the events has not been explored; however, there is no doubt that by competing at events around the country there is a substantial economic contribution through event tourism activity. Following a "circuit" is well documented in early literature (Colquhoun \& Machell, 1927; W. Gibson, 1882; McCombie Smith, 1891) where competitors travel to multiple events. Traveling between events is not exclusive to Highland Games and is an activity that has endured since before early Greek civilizations where increased competition and professionalization of sport increased travel (Torkildsen, 2005). Furthermore, in July consecutive Highland Games take place over a 9-day span providing ample opportunity for traveling competitors to compete at multiple events. As determined in this research the presence of international and domestic competitors contributes to the variety and uniqueness of these events in Scotland.

A series of in-depth interviews explore the unique perspective of organizers in Scotland where Highland Games are presented as a cultural community occasion showcasing competitive elements of indigenous Highland culture. The literature provides little insight into these phenomena in Scotland although there has been some interest in Highland games within diasporic communities, in North America by authors such as Chhabra (2004), Chhabra, Healy, and Sills (2003), Chhabra, Sills, and Cubbage (2003), Crane, Hamilton, and Wilson (2004), Donaldson (1986), Flinn and Turner (2014), Mason (2007), and Ray (2001). Redmond (1982) provided a general account of Scottish sporting activities in 1800s Canada, whereas more recent literature by authors such as by Bueltmann (2012), Patterson (2012), and Ruting and Li (2011) pertained to events in Australasia. The literature suggests that Highland Games staged outside Scotland generate greater academic interest than Scottish-based events. This study, in some part, redresses this and contributes to the literature on organization and management of community events.

The distinguishing attribute of this research is the content is based on primary data collected from a number of interviews whereas the following literature is more an overview of Highland Games. Authors such as Webster $(1973,2011)$, who provides the most informative account of Scottish Highland Games, recounting the history and evolution of the events and key competitive activities. Some mention of individual events is distinguished alongside reference to specific Scottish and international sporting champions. Other significant authors of Highland Games from a social science and sporting or nationalistic perspective are Jackson (1998), Jarvie (1991), and Tranter (1987, 1989, 1998), athletic activities and the achievement of athletes (Allan, 1974; Donaldson, 1986; McCombie Smith, 1891), specific events (Airth Highland Games Committee, 1984; Colquhoun \& Machell, 1927; McIntosh, 2008; Zarnowski, 2005), regional events (Knox, 2003, 2008), management and organization by Reynolds, and from a general perspective by Brander (1992), Grant (1961), and Macdonell (1937). The most prolific contributor to the literature on Scottish Highland Games is Jarvie (1989, 1991, 1994, 2000, 2003a, 2003b, 2005, 2006), Jarvie and Burnett (2000), and Jarvie and Reid (1999a, 1999b), exploring themes relating to sport, politics, communitarianism, nationalism, and the North American émigré.

Unique cultures are increasingly used to stimulate cultural tourism and increase visitor and touristic activity, and events that offer a unique cultural experience are often incorporated into event strategies to broaden tourist appeal. As cultural tourism is one of the fastest growing forms of tourism, destinations benefit when visitors have the opportunity to experience unique cultural settings, thereby sustaining cultural practices. Furthermore, indigenous cultural festivals are celebrations of local culture reconfirming a sense of identity through shared values (Donlon, Donlon, \& Agrusa, 2010; Page \& Connell, 2012; Whitford \& Dunn, 2014) where residents are the central component. In the case of Highland Games and every competitive event, the competitors are key to a successful outcome although the 
alignment with Scottish culture is distinctive from many mainstream competitive events.

\section{Literature Review}

Community events are primarily staged for the benefit of local residents where creating an enjoyable social experience is often the optimum goal. The event experience can be an amalgamation of unique traditional and cultural themes that celebrate local identity and bring sociocultural and economic benefits to a destination. There is a certain social value attached to community events as a motivator for community involvement, to strengthen community bonds, provide sociocultural benefits, and celebrate community values.

The sharing of culture and beliefs lead to increased social interaction (De Bres \& Davis, 2001; Gelder \& Robinson, 2010; Jamieson, 2014; Mayfield \& Compton, 1995; McCleary, 1995; O’Sullivan \& Jackson, 2002) and the creation of collective community memories. Of significance are individuals who return as visitors with familial connections, to reconnect with family and friends engendering loyalty to a place through event attendance (Akhoondnejad, 2016; Devismes, 2014). Notably, community events reunite past residents, family, and friends who use festival and event spaces to meet for social reunion to create shared experiences, values, and beliefs (Brewster, 2014; Dimmock \& Tyce, 2001; Gelder \& Robinson, 2010; Jamieson, 2014; Light, 1996; Pegg \& Patterson, 2010; Ziakas \& Costa, 2010), which, through social interaction, leads to increased engagement and collective efficacy within communities. Such reunions are likely to contribute significantly to shared emotions and the creation of memorable experiences as found by Wood and Kenyon (2018). A similar theme exploring senses and emotions was found by Christou, Sharpley, and Farmaki (2018) to be linked to event satisfaction. A particularly poignant theme when referring to former residents returning to a community where previously shared experiences may be revisited by familiarity of the temporal and spatial places within festivals and events.

The uniqueness of community events may appeal to heterogeneous audiences as a collective celebration. Although there are likely to be residents that are disengaged because it is unlikely that all community members will attend a local event such as minority groups or others with a general disinterest in the event (Azara et al., 2018; Bagiran \& Kurgen, 2016; Boo, Carruthers, \& Busser, 2014; Rogers \& Anastasiadou, 2011). Unsurprisingly, Derrett (2005) found the sustainability of cultural community events improved if the local population is supportive of the event. Furthermore, when applying the motivation-opportunity-ability model to gauge community engagement and participation at local festivals, Jepson, Clarke, and Ragsdell (2014) found that sustainability can be achieved when the local population is actively engaged in the planning and decision-making process of events. However, if the value of events is perceived to be unsatisfactory by local businesses and residents there is likely to be less loyalty and support for the event.

The role and support by governance for community events can be vital to sustain nonprofit events that support sociocultural dimensions of a population. For example, research requested by the Scottish Government involved some elements of Scottish indigenous sport, which included Highland Games (DTZ Research, 2007), although there were no obviously perceived benefits for Highland Games from this study. Government policy has a central role to play in supporting festivals and events; therefore, Lee, Liu, Chung, and Ho (2015) argued that local authorities and government policy should support festival management of small culturally driven community events. Moreover, as defined by Wood (2005), measuring social and economic impacts of local authority supportive events is a beneficial tool when setting economic and social objectives for future events. To better understand the perceived impacts to the host community from an organizational perspective, Gursoy, Kim, and Uysal (2004) explored four key socioeconomic dimensions that were community cohesiveness, economic benefits, social incentives, and social costs, where the findings placed social benefits ahead of cost for the residents. However, economic impacts cannot be entirely disregarded because community events can appeal to an audience that extends beyond local boundaries and can bring substantial economic benefits to the residents (Baptista Alves, Cerro, \& Ferreira Martins, 2010; Brewster, 2014).

By developing links between community events and local authorities and interlinking management 
with policy a stronger foundation of support can be established for events and festivals (Ziakas, 2013). Additionally, Mair and Whitford (2013) proposed that robust relationships between events and a suitable public policy agenda may increase community engagement with events. Where there were policies to strengthen the sense of community and reduce social isolation, Mair and Duffy (2015) found a growth in the number of community festivals.

Like many community events, most Highland Games operate on a not-for-profit basis where the reliance and enthusiasm of volunteers and contribution to community spirit is measurable. When approaching the parameters of event organizers there are many themes and associated areas of interest, such as social capital, group identity, and associations with community and place. The association between organizing groups of community events is expressed by Andersson and Getz (2009) as characteristic of the not-for-profit sector where benefits to the local community are the central common goals, where the volunteer workforce contributes to social cohesion, national identity, and pride. The organization of community events includes volunteers and often results in the reliance of a small number of people (Bendle \& Patterson, 2008) and is typical of community-based voluntary organizations where, although there may not be commitment issues by the organizers, there can be difficulty recruiting new members. Some volunteer and community groups can be very effective at event operations due to the high levels of commitment and hard work (Brewster, 2014). Furthermore, Davies (2015) expressed that leadership qualities developed extend beyond the spatial and temporal limits of the event. Many events, in particular community events, would be unable to operate if it were not for the organizers who drive the management process as an essential volunteer workforce.

The creation of social capital is a central theme of community events where the need to form networks initiates bonding within an organization leading to a sense of belonging (Darcy et al., 2014). There is growing interest in the organization of sporting events and social capital and how social capital develops through organizing, coordinating, and participating in an event (O'Sullivan et al., 2008). Furthermore, Zakus et al. (2009) found evidence of the creation of social capital within the volunteer organizers of sports clubs, affirming positive development for individuals within the community that have affiliation to the sports.

It is not generally a key objective for community events to target visitors and tourists although Litvin (2013) extols the need for event organizers to elevate events beyond the locality of community to increase tourist spending for local businesses. Organizers of successful events are more likely to work collaboratively and build collective community memories.

\section{Method}

The foregoing literature presents an overview of themes within community festival and event research. This study employs a qualitative research technique in the form of in-depth interviews, which is fitting when operating within a social context from an interpretivist perspective. The data were collected as part of a wider study that investigated Highland Games in Scotland where the overall aim was to explore the management of the events and associated touristic activity. With a key focus on the structure of Highland Games in Scotland, the internal and external challenges faced by the volunteer organizers and collectively, the contribution to event tourism in Scotland (Brewster, 2014).

The philosophical underpinning is centered within a qualitative paradigm to explore the social relationships between individuals and how that social world develops. Following an interpretivist approach allows comprehensive understanding of the research topic through inductive reasoning (Pyke, Hartwell, Blake, \& Hemingway, 2016). The interviews were conducted, recorded, and transcribed by the sole researcher in a timely fashion to ensure data was appropriately captured. Thereafter, the interviews were read and reread before being cross-referenced and as all respondents are experts (i.e., actively involved in management and organization of separate events), the data was deemed appropriate and accurate and contributed to the robustness of the data collection. Bryman (2008) cited four key areas as a means of corroborating the findings, which are: credibility, achieved by following good practice; transferability by producing rich descriptive accounts; dependability where complete records of all phases are maintained; and finally, 
conformability whereby the researcher remains objective by not allowing personal values to influence the research gathering process or the findings derived from the analysis. In this instance, all four aspects were built into the research process. Previous communication between the researcher and respondents eliminated problems associated with trust to allow a relaxed informal discussion and minimize most issues of trust to establish credible validity (Gray, 2014; Silverman, 2006; Veal, 2011).

A combination of convenience and purposive nonprobability sampling techniques were employed to gather data from organizers and experts of Highland Games. Although purposive sampling may be considered unsuitable due to the potential for bias and lack of theoretical meaning (Malhotra \& Birks, 2007) it is common practice when conducting qualitative research when the need for expert knowledge is required. Although the respondents were selected by a nonrandom process and therefore cannot be generalized to the wider population, there is strength in the expertise and robustness of respondents which gives validity to the findings.

The selection process for the respondents was based on an initial exploration of Highland Games organizations in Scotland and direct communication identified individuals suitable for recruitment with interviews conducted over a 4-month period. All respondents are active members involved with organizing Highland Games and considered to be experts, therefore able to recount real and unique perspectives of the events. The interviewees were chosen based on their geographical location to ensure representation of small and large, urban and rural events across Scotland and to reach a proportionate sample of respondents across Scotland (Bloch, 2009; Gray, 2009; Malhotra \& Birks, 2007). To correspond with the number of events where surveys were distributed, a total of 16 respondents participated and because Highland Games operate in a very select environment where most of the people are known to each other it is necessary to restrict the interviewees' direct associations with specific events to safeguard anonymity. In a maledominated environment to include gender as a descriptor is likely to lead to the identification of any female participants; therefore, the respondents are individualized by numbers because there is a high possibility that some of the participants were aware of others participating in the research. Collectively the interviewees are referred to as the "organizers."

The duration of the interviews was between 45 min and $1 \mathrm{hr}$, allowing sufficient time for the topics to be explored in depth and provide a substantial data set (Gray, 2009; Iacobucci \& Churchill, 2010). To eliminate bias, the same amount of time was allocated to all respondents and the interviews followed a standardized semistructured format. In keeping with qualitative research principles, the semistructured interviews were loosely guided by a set of topics and all interviews were digitally recorded and transcribed verbatim by the researcher. Key topics had previously been identified as competitive activity and different aspects of committee organization and management, which were employed as a guide when developing the questions. By expressing opinions, the interviewees disclosed a rich stream of knowledge to deepen understanding of the events from a management and organizational perspective.

The resulting data were analyzed manually following an iterative process and a thematic framework facilitated themes to emerge inductively. As each interview was assessed information was added to the framework slowly building content until all interviews had been processed. A systematic procedure followed charting data into the framework matrix prior to mapping, interpretation, and contextualization through a process of sifting and sorting (Gale, Heath, Cameron, Rashid, \& Redwood, 2013; Ritchie \& Spencer, 2002). The data gathering exercise elicited a rich source of data providing unique data sets from each individual pertaining to attitudes, experiences, and perceptions of Highland games.

\section{Findings}

Central to a successful Highland Games are the competitors and is presented in the findings as a key theme, along with community associations and committee operations. In the first section attention is initially given to the importance of competitors. The second section addresses the community nature of the events, which operate on a not-for-profit basis and the final section turns to the committee as the organizers of the individual events. Each interviewee provided perceptions of their own individual 
event $(n=16)$ and areas of national interest to provide an overview of the events in Scotland.

\section{Scope of Competitive Activity}

It is important to reaffirm the cultural significance of competitive activity at Highland Games to include, but not restricted to, bagpipe music, Highland dancing, track and field athletics, and heavy events such as hammer throwing and tossing the caber. When asked about the breadth of competitive activity at the games Respondent 2 proposed:

The whole spread if possible [all competitive activity], you would have the heavyweight events, the focus of the games, then you would have the light events, the running and the field events, high jump, long jump, pole vault if possible. . . Highland dancing, again another focus, a huge contributor, colorful and musical, solo piping if you can, not such a big attraction but it's very much part of the games' history and pipe bands, not necessarily a competition but pipe bands have to be there just as an attraction. Certainly, involve children's events because it is a community event ... kids are just as entertaining as your top professional athletes and provide just as much fun . . . kids races are a great event.

As the competitive activities vary across the events, so does the expertise of competitors including elite professional athletes to amateurs and locals. Given the option, many elite athletes, such as the heavy event athletes, may choose to compete at the most prestigious events, or events that offer the highest prize money. The number and scale of events ensures that the less accomplished competitors have ample opportunity to hone their skills at nonprestigious events. Elite and nonelite competitors are equally important although it would seem the spectators are less concerned about elite competition in favor of the spectacle and competition. Similarly, Hinch and Higham (2005) suggested that the presence of elite athletes at sports events is unlikely to have undue influence on spectator numbers and it is unlikely that many competitors at Highland Games are well-known outside their disciplines, although Scottish competitor Mark Dry won a bronze medal for the hammer throw at the Commonwealth Games in Glasgow, 2014 and at the Gold Coast Commonwealth Games in 2018
(Jardine, 2018) and is a familiar figure as a heavy event athlete at Highland Games in Scotland.

There are Highland Games that attract less than 1,500 spectators (Brewster, 2014; Brewster et al., 2009) but the implication is that Highland Games could accommodate higher numbers of track and field athletes. Most of the commentators cited all competitive activity as equally important in order to provide the kind of spectacle and entertainment the audience expects, explained by Respondent 2:

It's not about purely athletes, it's about all the disciplines, you know, solo piping, pipe bands, running, tug o' wars, your heavyweights and a very central thing too are the kids' races, the participation of kids in the event . . . you won't get everyone out to go and watch heavyweights, nor just watch dancing, but the whole amalgam.

Overseas competitors are frequently seen participating at events and bring with them an added dimension to the content as well as implications for the economic benefits of event tourism.

Scotland is unique as the home of Highland Games and as such attracts competitors from around the world. There are opportunities to compete overseas at Highland Games in countries such as the US, Canada, Australia, and many other global destinations. When asked about the participation of overseas competitors, Respondents 15 and 16 confirmed individual international competitors present in all disciplines. Although there are also groups of competitors traveling with a supporting entourage to multiple events as proposed by Respondent 11:

Sometimes, dancers usually, if they're coming over on holiday sometimes they'll come two or three families at a time, there might only be one or a couple of dancers in it but you then get groups.

This provides evidence that international competitors are found at numerous events and follow a "circuit" around the country as confirmed by Respondent 7 who suggests that over a 2-week period the international competitors choose a number of events to attend. Traveling between destinations to compete at multiple events is a practice that has been taking place since before early Greek civilizations when competitors traveled between villages to compete (Torkildsen, 2005). Heavy event athletes, pipe bands, and Highland dancers are the 
highest profile international competitors with many taking advantage of their time in Scotland by following a circuit to compete at a number of different events. The movement of competitors is well documented (Brander, 1992; Colquhoun \& Machell, 1927; W. Gibson, 1882; McCombie Smith, 1891; Webster, 2011), although not always welcome as lamented by Macdonnell (1937) who was concerned that professional athletes followed a Highland Games circuit to maximize their winnings.

Respondents 4, 7, 8, 9, 11, 13, 14, 15, and 16 all indicated groups of international competitors were present at their events, predominately the disciplines of heavy events, Highland dancing, and pipers. With competitors traveling from Australia, Canada, New Zealand, South Africa, France, Germany, Netherlands, Ireland, and England. The researcher encountered a number of international track and field athletes, heavy athletes, Highland dancers, pipe bands, and cyclists specifically traveling to Scotland to compete at Highland Games, who are contributing significantly to the Scottish economy. Recent research suggests that, overall, Highland Games contribute $£ 25$ million to the Scottish economy (Campsie, 2018).

When collecting data, the researcher encountered a group of 85 Canadians comprising Highland dancers from a single Dance School, and pipe bands who traveled to Scotland specifically to compete at multiple Highland Games and returned every 4 or 5 years. Another group of 32 Canadian Highland dancers and pipers were also encountered and extended to 12 Australian track and field athletes and cyclists who were competing at a number of Highland Games over a 2-week period. Once the Highland Games calendar commences there are events nearly every Saturday and Sunday with multiple events taking place during July and August. An added incentive is perhaps the 9-day window of opportunity in the middle of July when there are events over a consecutive 9-day period.

\section{Committee and Community Associations}

Typically, community events such as Highland Games strive to create space for an inclusive environment. It is common knowledge that community events require the support of the host community to remain sustainable and claim their place on the annual events calendar. The relationship between the organizers and the local community is important to foster reciprocation between events and the resident community. The general consensus of the respondents signifies that first and foremost the events are staged for the entertainment of the host population, although visitors and tourists are equally welcome. There was some considerable acknowledgement of community support by all respondents although the event of Respondent 15 targeted tourists as well as community.

This reflects the findings of Harlambos and Holborn (2008) and Mohan and Mohan (2002), who found stronger evidence of social capital within small communities where the community's affiliation for the event exemplifies the mutual support extolled by the exponents of social capital. There were even suggestions that up to a certain threshold, smaller communities are better equipped to stage more meaningful events for the local residents as explained by Respondent 10 :

They're community events, ... that's the day every year when whether it be the local fête or whatever, in some areas it's the Highland Games. . . . So, you've got the local traditional events which historically have been held there and they're for locals but then the other side of that, some of the bigger games are really appealing to the overseas market or visitors . . . it's a day out for them being there.

A key element of Highland games is that they take place on the same day each year, such as the second Saturday in July and are an important annual feature for many communities. Respondents $2,12,14,15$, and 16 held similar points of view whereby the events are run by the local community for the local community and in many cases an important and long-established fixture within small rural locations.

There is a general consensus that it is the people, the local community, and all the individuals that come together as a singular extended community in its entirety that provide the essence of Highland Games. As described by Respondent 16:

Where do the games fit within the communities in which they are held? It's community development, it's community enterprise. It's collectively doing something well together and I think that's 
quite important, a bit of glue keeping communities together.

The idea of individuals working together builds community value through the creation of social capital adding to community well-being corresponding with Blackshaw (2009), Halpern (2003), Portes (1998), and Sharpley and Stone (2012).

A few events have evolved or moved away from a centrally based community event sometimes with deliberate intention to target tourists and visitors from a wider environment. Even so, community ties are strong when associated with Highland Games and the link between community and the events was evident during the interviews, although there is acknowledgment that visitors and tourists bring a welcome added dimension to the events. The support extends beyond the intangible sense of community where the cultural content appeals to visitors and tourists. Because the majority of respondents found visitors and tourists at their own events provides further proof that community events can appeal to wider audiences. Furthermore, this research found evidence of a substantial number of tourists at all the events in this study (Brewster, 2014). Brewster (2014) also found evidence of support from returning community members, friends, and relatives who contribute to the diasporic community and confirmed by Respondent 16 who states "there are a lot of people who come back to the village for games' day." The presence of former residents, family, and friends at Highland games was also found by Jarvie (2003a), where the event is the primary motivator to travel. Every Highland Games is unique in location and content and it may be the differences between the events that motivate individuals to travel to multiple events in one season or across a number of years.

Most Highland Games operate with a standard committee of volunteers who donate time, energy, and skills, working behind the scenes to organize and manage the events. There can be specific challenges related to a volunteer workforce as found within the realms of Highland Games' organizers by Reynolds, where bringing new members to committees was challenging. The general format of organizations operating within a formal committee structure is that official bearers remain in place for a certain term and replaced by other elected members on completion of that term. However, it is apparent that the succession of appointed members is quite different as commented by Respondent 16 when referring to the changeover of elected committee members:

It [committee age] tends to be older . . . there are a lot of people who are retired and so I would say you would probably find the average age of sort of 60 ish but there are a lot of people also sort of semi-retired.... I think it is difficult to get younger people involved in that because they tend not to have the time.

Although the challenge of appointing new committee members is a real problem the respondents were vociferous in agreeing the benefits of older long-term members as explained by Respondent 1 : “There's several hundred years' experience . . . there are one or two younger ones, but by and large, a lot of experience on that committee." A sentiment shared by Respondents 1 and 13 where some committee members have been involved in running the games for many years. Although the depth of knowledge and expertise held by longstanding members was recognized, some concerns were expressed by Respondents 1, 2, 4, 8, 11, 14, and 15 associated with the ability of ageing members to carry out the physical work required to set up the events. It is common for the average age of committee members to be around 60 years and with increasing numbers of septuagenarians and octogenarians serving on committees the physical challenges are understandable.

The suggestion that long serving committee members can be a good thing is corroborated by Respondent 1: "a lot of them (events) have worked with the same committee members, diehard committee members and have maybe run the games for 20 years." The implication is that not everyone who is a long-serving committee member wants to leave and may be linked with the social aspects of volunteering or reliance on enthusiasm as expressed by Gursoy et al. (2003). The sense of commitment is a recurring theme as Respondent 7 explained:

\footnotetext{
They tend to stay, once you're in with the games you tend to get hooked and you definitely stay ... it's difficult nowadays ... to get people to come on to the committee especially because it's voluntary.
} 
The commitment by acting committee members contribute to successful event operations where volunteer community groups can be very effective due to high levels of commitment and hard work. The reliance on a small number of dedicated individuals replicates the findings of Bendle and Patterson (2008) and Gursoy et al. (2003), where enthusiasm is the mainstay and commitment to the group increases with the length of service, even when elderly committee members are unable to equally contribute to the preparations. Although there appears to be a number of older committee members keen to continue to organize Highland Games, there are others who may prefer to leave but do not feel that is a viable option.

\section{Recruitment and Sustainability}

The theme of recruiting new members emerged as evidence concludes there is some reluctance to leave the committee prior to appointing a new member, even when committee members may not want to remain on the committee ad infinitum as explained by Respondent 5 :

Often committee members stay on the committee because they are committed to the games and realize that if they were to leave the committee there's nobody else really to replace them. So . . over the years I can think of a few people who wanted to give it up but haven't been able to give it up because there's nobody else to do the job.

\section{Contrastingly, Respondent 2 stated:}

Most of the lads here ... it's such a long history that they want to keep it going, that's the great thing, bring in youngsters onto the committee ... the youngsters want to come on in the country areas, they want to put that in, it's seen as a great thing to belong to the local games. You need to keep feeding in youngsters all the time if you want anything to continue.

Formal committees rely on a steady succession of new recruits to replace retiring members and fill the formal positions; for example, chairman, secretary, and treasurer. The difficulties attracting new members and some of the misconceptions of potential members may be a barrier to recruitment. The inability to increase committee member numbers and introduce younger members is a concern for some, as explained by Respondent 10:

The next generation don't seem to have the same interest, but as they get older that might change, but at the moment my concern would be, who's going to take it on? Who's going to keep it going?

The difficulty found by some organizations to attract younger or new members is potentially fateful to the future of the events and is typified by Bendle and Patterson (2008), where events are dependent on a relatively small number of organizers. If unable to recruit new members places there are increasing demands on existing committees, perhaps not in the sense of knowledge and experience, but certainly the physicality required to set up the event is a challenge for some of the older members. Other barriers relate to management, skills, and knowledge and the perceptions of the committees as offered by Respondent 15:

They [community] might see it [Highland Games] as some sort of specialism that people couldn't learn, maybe think it's a sort of closed society, you know you've got a committee ... everybody's got to start somewhere.

Another potential problem was identified by Respondent 3, who disclosed that as a relatively new participant, the individual found they were "up against a form of entrenchment through tradition, it's always been done like this, it's always worked."

Respondent 9 simply stated when referring to recruiting new members "It is difficult to get folks. . . . Very much a problem," perhaps exacerbated by the volunteer status of committees as noted by Respondent 7:

It's difficult nowadays . . . to get people to come on to the committee especially because it's voluntary. ... We're slowly getting younger ones in now but it's a struggle, it's a real struggle to get younger people interested in Highland Games, to give their time up . . . they don't want to do the voluntary bit.

Respondents 5, 14, and 15 expressed similar difficulties when recruiting new members, with comments such as: "it's hard to attract people full stop ... it's usually down to a band of committed volunteers who tend to stay for quite a number of 
years" (Respondent 5); “He's always going to pack it in, but he never does, nobody seems to want to do it" (Respondent 14); and It's quite difficult to get them [committee members] ... it's the same people that have been doing the same job now . . . he's retired in his late sixties ... he's got nobody to take his place. (Respondent 15)

There are variations of successful recruitment of new, younger members resulting in situations where current members feel unable to retire, partly due to concerns relating to the capability of a reduced number of members managing the event. The commitment demonstrated is tangible in that the prime purpose is without doubt the future continuance of the events. The relationship between committee members support for the organization and fellow members suggests evidence of social capital associated with individuals, groups, and organizations proposed by Arcodia and Whitford (2008), Putman (1993), O'Sullivan et al. (2008), and Seippel (2006). However, the findings allude to elements of exclusion if potential committee members do not feel they belong or that the organization is somehow elitist and engenders apprehension by outsiders as found by Blackshaw (2009), Halpern (2003), Portes (1998), Putman (1993), Taylor (2011), and Tonts (2005) in relation to social capital.

Some committee members would gladly hand over the reins to new and younger members, although it is suggested that other members remain through choice, even if not capable of contributing fully in all aspects of the organization and management of the events. Crucially, within the management processes a network of contacts and individual expertise is developed, which is invaluable although does not alleviate the difficulty to recruit new members, which remains a constant underlying theme for most events.

Although difficult to determine without further research there were a few reasons stated as to why new members were not coming forward. One perception is that some of the committee had been part of the organization for such a long period of time they were reluctant to change, which may be perceived by potential new members as a deterrent as longer-serving committee members may stifle new ideas. The notion that membership was a closed shop, or an old boys' network was also highlighted as a possible deterrent. However, even although some of the respondents highlight this as a potential issue, they did not share the same views suggesting some misconception between the community and the organization.

A general lack of interest in Highland Games was also cited as a deterrent to new members, or a fear of the unknown where it is thought that some kind of expert knowledge is required to even approach the committee. In some instances, it is suggested that the host community are unaware of the problems the organizations have in recruiting new members, or that no help is required. Finally, the younger generation may not have the time or inclination to be involved in a voluntary capacity that requires substantial time and effort. Further research is required to explore the reasons why it may be difficult to recruit new members from within the community.

The not-for-profit organizers of Highland Games find themselves in similar situations with comparable outdoor, community event organizations. The organizers not only have to contend with adverse weather but negotiating legislation and contesting elements that may impact on the event and spectacle is likely to be an ongoing process, particularly when successive governments continue to reshape the endeavors of previous administrations.

\section{Discussion and Conclusions}

Although this research is set within Highland Games, many community events are based on a similar committee membership format and as such are likely to face similar challenges. Particularly, as a sustainable committee membership is key to the events' successful management and organization. As with any event the support, level of contribution from the community, and content of sufficient interest is crucial in terms of production.

Athletics, music, and dance are the core competitive activities at Highland Games, determining the cultural base that appeals to national and international competitors. Therefore, it is important for the organizers to include activities that appeal to a broad spectrum of competitors and spectators. Some events are renowned for high level and prestigious competition whereas others are localized and are less competitive in terms prize money. As with most competitions, the competitors have a variety of skill levels and the diversity and range of events across 
Scotland ensure many opportunities for competitors of any skill level to compete. The variance of expertise between the elite professional athletes, amateurs, local competitors, and others provide opportunities for the less advanced to hone their skills before advancing to events that are more prestigious. Even although not all events attract elite competitors it is not considered a disadvantage, mainly because the spectators may be unaware of the presence of elite competitors. Therefore, the element of competition is important to the audience, although there is capacity to increase the presence of track and field athletic clubs at some events. Maybe Highland Games are not perceived as venues for light track and field competition although the inclusion of a triathlon at Loch Lomond Highland Games is likely to broaden appeal for triathletes.

Although international competitors are a significant presence at sporting events, the competitive element can be a major attraction for tourists such as Dragon Boat races in China (Mccartney \& Osti, 2007), the Nadim Festival in Mongolia (Thompson \& Schofield, 2009), or camel racing and wrestling in Turkey (Donlon, Donlon, \& Agrusa, 2010). The contribution of competitors is essential to the success of any sporting event. Fortunately, the interest in competing at Highland Games is evident nationally and internationally, where both sporting and bagpipe music are keenly contested by domestic and international pipers. As noted by the researcher groups of international competitors were present at a number of events, which may be associated with the number of Highland Games that are staged outside Scotland.

There is overwhelming evidence that determines extremely strong links between the organizers and the host community through frequent comments relating to the importance of community as a focal point of the events. The community is not only an important source of demand for the events but also as suppliers through the efforts of volunteers as part of the organizational workforce. The general consensus is that these culturally based community events have related meaning for the host community; therefore, are better supported than other events because one of the many facets of Highland Games is their ability to mobilize communities.

The events are individual and unique mostly due to local communities organizing traditional events for the entertainment of the local residents, although the indigenous nature of the sporting, musical, and dancing content undeniably attracts visitors and tourists. There is a real emphasis on the ability of Highland Games to pull communities together that benefit residents beyond the event. Records suggest that some of these events have been staged for over 200 years (Brewster, 2014) and are a well-established focal point for the community that reunites former residents who return specifically for these events. Although the majority of organizers associate the events first and foremost with a community focus, a minority suggest their own event has outgrown, or moved beyond simply being a community event to specifically appeal to a broader tourist market. There is a sense of community strength and cohesion more so in small villages or urban environments where strong social networks foster mutual obligations between people as proposed by, and associated with group membership (Blackshaw, 2009; Bourdieu, 1985; Burt, 2000; Coleman, 1988; Giddens \& Sutton, 2009; Halpern, 2003; Harlambos \& Holborn 2008; Mohan \& Mohan, 2002). The suggestion that event organizers are equally welcoming to tourists and visitors demonstrates evidence of social capital as proposed by Bourdieu (1985), Harris (1998), Portes (1988), and Torche and Valenzuela (2011).

The purpose of this research and principle outcome is to better understand the managerial implications for community event organizers. For instance, it is perhaps surprising the seemingly fragile nature of committee membership, in terms of sustainability and challenges associated with attracting new members. Furthermore, it is useful for event organizers to understand the dynamics of committee membership from an organizational and management perspective of small community events.

Limitations of this study is the focus on Highland Games, although it is important to note that these challenges are likely to arise in any committees tasked with the management and organization of community events. Additionally, because the data were qualitative it has not been quantified. The results define some of the key aspects faced by contemporary committees with many resolute in the view that the events are run for the community by the community. One of the recurring themes is the difficulty some events encounter in their quest to attract new and younger committee members, which may be a common occurrence within not-for-profit 
community organizations. However, this is of less concern to small rural communities with a long tradition of Highland Games and supported by the majority of residents than even long-established events neighboring or set within urban areas. The one key area that is crucial is to introduce new members to the committee so that more experienced organizers can pass on their knowledge or expertise, thereby ensuring valuable knowledge remains within the committee. It is one area under the control of the organizers and perhaps may require further exploration to comprehend why there appears to be some detachment in the succession planning to recruit new members. The seemingly reluctance to join Highland Games committees may be a misperception of the events. Where the core sporting and competitive activities are overshadowed by the tartan and heritage perspective, which may not appeal to potential younger members. The findings of this study confirm the need to understand organizational implications when managing small community events, particularly when there are historical or cultural associations with communities. Although this study focused on Highland Games and the views of the managing committees, there are implications for committee-led not-for-profit community events. There are likely to be many similar not-for-profit organizations operating throughout the world that have to adhere to specific regulations to be legitimized. In order for community organizations to be legitimate and transparent in Scotland, some of the central actions required are that key members are elected at Annual General Meetings, a constitution is developed, financial records are retained, meetings are recorded through minutes, and a meeting schedule exists. Furthermore, to meet legal requirements as a charity in Scotland and attest the organization is being run properly, not-for-profit organizations register with the Office of the Scottish Charity Regulator (OSCR). Thus, although this research is based on Scottish organizations the study could be extended to other events to provide further insights of the organization and management of community events.

\section{References}

Airth Highland Games Committee. (1984). The story of Airth Highland Games. Stirling, Scotland: Stirling Printing and Publishing.
Akhoondnejad, A. (2016). Tourist loyalty to a local cultural event: The case of Turkmen handicrafts festival. Tourism Management, 52, 468-477.

Allan, C. (1974). The games; a guide to Scotland's Highland Games. Alexandria, Scotland: Famedram Publishers Ltd.

Andersson, T. D., \& Getz, D. (2009). Tourism as a mixed industry: Differences between private, public and not-forprofit festivals. Tourism Management, 30(6), 847-856.

Arcodia, C., \& Whitford, M. (2008). Festival attendance and the development of social capital. Journal of Convention and Event Tourism, 8(2), 1-18.

Azara, I., Wilthsier, P., \& Greatorex, J. (2018). Against all odds: Embedding new knowledge for event continuity and community well-being. Event Management, 22(1), 25-36.

Bagiran, D., \& Kurgen, H. (2016). A research on social impacts of the Foça Rock Festival: The validity of the Festival Social Impact Attitude Scale. Current Issues in Tourism, 19(9), 930-948.

Baptista Alves, H. M., Campón Cerro, A. M., \& Ferreira Martins, A. V. (2010). Impacts of small tourism events on rural places. Journal of Place Management and Development, 3(1), 22-37.

Bendle, L., \& Patterson, I. (2008). Serious leisure, career volunteers and the organisation of arts events in a regional Australian city. International Journal of Event Management Research, 4(1), 1-10.

Blackshaw, T. (2009). Social capital. In T. Blackshaw \& G. Crawford (Eds.), The SAGE dictionary of leisure studies (pp. 192-193). London, UK: SAGE Publications Ltd.

Bloch, A. (2009). Doing social surveys. In C. Seale (Ed.), Researching society and culture (pp. 163-178). London, UK: SAGE Publishing Ltd.

Boo, S., Carruthers, C. P., \& Busser, J. A. (2014), The constraints experienced and negotiation strategies attempted by nonparticipants of a festival event. Journal of Travel \& Tourism Marketing, 31(2), 269-285.

Bourdieu, P. (1985). The forms of capital. In J. G. Richardson (Ed.), Handbook of theory and research for the sociology of education (pp. 46-58). Westport, CT: Greenwood Press.

Brander, M. (1992). The essential guide to Highland games. Edinburgh, Scotland: Canongate Press plc.

Brewster, M. (2010). The Scottish Highland Games as a cultural event. In S. J. Page \& J. Connell (Eds.), Leisure, an introduction (pp. 360-364). Essex, UK: Pearson Education Limited.

Brewster, M. (2014). A study of Scotland's Highland games: Traditional sport and musical competition in the twentyfirst century (Ph.D. thesis). University of Exeter.

Brewster, M., Connell, J., \& Page, S. J. (2009). The Scottish Highland Games: Evolution, development and role as community event. Current Issues in Tourism, 12(3), 271-293.

Bryman, A. (2008). Social research methods. Oxford, UK: Oxford University Press.

Bueltmann, T. (2012). The image of Scotland which we cherish in our hearts: Burns anniversary celebrations 
in colonial Otago. Immigrants and Minorities, 30(1), 78-97.

Burnett, J. (2000). Riot, revelry and rout: Sport in lowland Scotland before 1860. East Linton, Scotland: Tuckwell Press.

Burt, R. S. (2000). The network structure of social capital. Research in Organizational Behaviour, 22, 345-423.

Campsie, A. (2018). Highland Games boost Scotland's economy by $£ 25$ million. The Scotsman. Retrieved from https://www.scotsman.com/lifestyle-2-15039/highlandgames-boost-scotland-s-economy-by-25m-1-4750217

Chappel, S., \& Loades, G. (2009). The camp oven festival and Australian identity. In D. Picard \& M. Robinson (Eds.), Festivals, tourism and social change, remaking worlds (pp. 191-208). Clevedon, UK: Channel View Publications.

Chhabra, D. (2004). Redefining a festival visitor: A case study of vendors attending Scottish Highland Games in the United States. Event Management, 9, 91-94.

Chhabra, D., Healy, R., \& Sills, E. (2003). Staged authenticity and heritage tourism. Annals of Tourism Research, 30(3), 702-719.

Chhabra, D., Sills, E., \& Cubbage, F. W. (2003). The significance of festivals to rural economies: Estimating the economic impacts of Scottish Highland Games in North Carolina. Journal of Travel Research, 41, 421-427.

Christou, P., Sharpley, R., \& Farmaki, A. (2018). Exploring the emotional dimension of visitors' satisfaction at cultural events. Events Management, 22, 2565-269.

Coleman, J. S. (1988). Social capital in the creation of human capital. American Journal of Sociology. Supplement: Organisations and Institutions: Sociological and Economic Approaches to the Analysis of Social Structure, 94, 95-120.

Colquhoun, I., \& Machell, H. (1927). Highland gatherings. London, UK: Heath Cranton Limited.

Crane, T. C., Hamilton, J. A., \& Wilson, L. E. (2004). Scottish dress, ethnicity and self-identity. Journal of Fashion and Management, 8(1), 66-83.

DTZ Research. (2007). An analysis of minority indigenous sports in Scotland. Retrieved from https://www2.gov. scot/Publications/2007/04/indigenoussports/indigenous

Darcy, S., Maxwell, H., Edwards, M., Onyx, J., \& Sherker, S. (2014). More than a sport and volunteer organisation: Investigating social capital development in a sporting organisation. Sport Management Review, 17, 395-406.

Darian-Smith, K. (2011). Histories of agricultural shows and rural festivals in Australia. In C. Gibson \& J. Connell (Eds.), Festival place; revitalising Australia (pp. 44-60). Bristol, UK: Channel View Publications.

Davies, A. (2015). Life after a festival: Local leadership and the lasting legacy of festivals. Event Management, 19, 433-444.

De Bres, K. D., \& Davis, J. (2001). Celebrating group and place identity: A case study of a new regional festival. Tourism Geographies, 3(3), 326-337.

Derrett, R. (2005). Why do regional community cultural festivals survive? Paper Presented to the Impacts of Events:
Triple Bottom Line Evaluation and Event Legacies: Third International Management Conference, University of Technology Sydney, July 13-15, Sydney, NSW.

Devismes, L. (2014). Regional events and festivals in Europe: Revitalizing traditions and modernizing identities. In U. Merkel (Ed.), Power, politics and international events. Socio-cultural analyses of festivals and spectacles (pp. 33-52). Oxon, UK: Routledge.

Dimmock, K., \& Tiyce, M. (2001). Festivals and events: Celebrating special interest tourism. In N. Douglas, N. Douglas, \& R. Derret (Eds.), Special interest tourism (pp. 355-383). Milton, Australia: John Wiley \& Sons Australia Ltd.

Donaldson, E. A. (1986). The Scottish Highland Games in America. Gretna, LA: Pelican Publishing Company, Inc.

Donlon, J. G., Donlon, J. H., \& Agrusa, J. (2010). Cultural tourism, camel wrestling and the tourism "bubble" in turkey. An International Journal of Tourism and Hospitality, 21(1), 29-39.

Finkel, R. (2010). "Dancing around the ring of fire": Social capital, tourism resistance, and gender dichotomies at Up Helly Aa in Lerwick, Scotland. Event Management, 14(4), 275-285.

Flinn, J., \& Turner, D. (2014). "Wha's like us?" Scottish Highland Games in America and the identity of the Scots' diaspora. In A. Jepson \& A. Clarke (Eds.), Exploring community festivals and events (pp. 92-105). Oxon, UK: Routledge.

Gale, N. K., Heath, G., Cameron, E., Rashid, S., \& Redwood, S. (2013). Using the framework method for the analysis of qualitative data in multi-disciplinary health research. BMC Medical Research Methodology, 13(1), 117.

Gelder, G., \& Robinson, P. (2010). Events, festivals and the arts. In P. Robinson, S. Heitmann, \& P. Dieke (Eds.), Research themes for tourism (pp. 128-145). Wallingford, UK: CABI Publishing.

Getz, D. (1991). Festivals, special events, and tourism. New York, NY: Van Nostrand Reinhold.

Gibson, C., Connell, J., Waitt, G., \& Walmsley, J. (2011). The extent and significance of rural festivals. In C. Gibson \& J. Connell (Eds.), Festival places; revitalising rural Australia (pp. 3-24), Bristol, UK: Channel View Publications.

Gibson, W. (1882). Highland sports and pastimes. Frank Leslie's monthly magazine. Retrieved from http://highlandgames.net/articles/pastimes1.html

Giddens, A., \& Sutton, P. W. (Eds). (2009). Introductory readings: Sociology (3rd ed.). Cambridge, UK: Polity Press.

Grant, I. F. (1961). Highland folk ways. London, UK: Routledge and Kogan Paul Limited.

Gray, D. (2014). Doing research in the real world (3rd ed.). London, UK: SAGE Publications.

Green, C. B., \& Jones, I. (2005). Serious leisure, social identity and sport tourism. Sport in Society: Cultures, Commerce, Media, Politics, 8(2), 164-181.

Greenwood, D. J. (1977). Culture by the pound: An anthropological perspective of tourism as cultural 
commoditization. In V. L. Smith (Ed.), Hosts and guests: The anthropology of tourism. Philadelphia, PA: University of Pennsylvania Press.

Gursoy, D., Kim, K., \& Uysal, M. (2004). Perceived impacts of festivals and special events by organizers: An extension and validation. Tourism Management, 25, 171-181.

Halpern, D. (2003). Social capital. Oxon, UK: Polity Press.

Haralambos, M., \& Holborn, M. (2008). Sociology, themes and perspectives (7th ed.). London, UK: HarperCollins Publishers Limited.

Harris, J. C. (1998). Civil society, physical activity and the involvement of sports sociologists in the preparation of physical activity professionals. Sociology of Sport Journal, 15(2), 138-153.

Hinch, T. D., \& Delamere, T. A. (1993). Native festivals as tourist attractions: A community challenge. Journals of Applied Recreation Research, 18(2), 131-142.

Hinch, T., \& Higham, J. (2005). Sport, tourism and authenticity. European Sport Management Quarterly, 5(3), 243-256.

Iacobucci, D., \& Churchill, G. A. J. (2010). Marketing research methodological foundations. Canada: Cengage Learning.

Jackson, L. (1998). Sport and patronage: Evidence from nineteenth century Argyllshire. The Sports Historian, 18(2), 95-106.

Jamieson, N. (2014). Sport tourism events as community builders: How social capital helps the "locals" cope. Journal of Convention \& Event Tourism, 15(1), 57-68.

Jardine, P. (2018). Mark Dry is bronze hammer hero again. Scottish Athletics. Retrieved from https://www.scottishathletics.org.uk/gold-coast-2018-sunday-april-8/

Jarvie, G. (1989). Culture, social development and the Scottish Highland Gatherings. In D. McCrone, S. Kendrick, \& P. Straw (Eds.), The making of Scotland, nation, culture and social change. Edinburgh, Scotland: Edinburgh U.P. in conjunction with the British Sociological Association.

Jarvie, G. (1991). Highland games: The making of the myth. Edinburgh, Scotland: Edinburgh University Press.

Jarvie, G. (1994). Royal games, sport and the politics of the environment. In G. Jarvie \& G. Walker (Eds.), Scottish sport in the making of the nation: Ninety-minute patriots? (pp. 154-172). London, UK: Leicester University Press.

Jarvie, G. (2000). Highland games. In G. Jarvie \& J. Burnett (Eds.), Sport, Scotland and the Scots. East Linton, Scotland: Tuckwell Press.

Jarvie, G. (2003a). Communitarianism, sport and social capital: Neighbourly insights into Scottish sport. International Review for The Sociology of Sport, 38, 139-153.

Jarvie, G. (2003b). Highland games, ancient sporting traditions and social capital in modern international communities. Studies in Physical Culture and Tourism, 10(1), 27-37.

Jarvie, G. (2005). The North American émigré. Highland games and social capital in international communities.
In C. Ray (Ed.), The transatlantic Scots (pp. 111-136). Tuscaloosa, AL: University of Alabama Press.

Jarvie, G. (2006). Sport, culture and society: An introduction. Oxon, UK: Routledge.

Jarvie, G., \& Burnett, J. (2000). Sport, Scotland and the Scots. Edinburgh, Scotland: Tuckwell Press.

Jarvie, G., \& Reid, I. A. (1999a). Scottish sport, nationalist politics and culture. Journal of Culture, Sport and Society, 2, 22-43.

Jarvie, G., \& Reid, I. A. (1999b). Sport, nationalism and culture in Scotland. The Sports Historian, 19(1), 97-124.

Jepson, A., Clarke, A., \& Ragsdell, G. (2014). Investigating the application of the motivation-opportunity-ability model to reveal factors which facilitate or inhibit inclusive engagement within local community festivals. Scandinavian Journal of Hospitality and Tourism, 14(3), 331-348.

Knox, D. L. (2003). Regional and national cultures in northeastern Scotland: Tradition, language and practices in the constitution of folk cultures. Retrieved from http:// etheses.dur.ac.uk/3655/

Knox, D. (2008). Spectacular tradition: Scottish folksong and authenticity. Annals of Tourism Research, 35(1), 255-273.

Lee, Y. K., Liu, T. L., Chung, F. T., \& Ho, H. H. (2015). Investigating the role of Government policy and the environment on locals' loyalty to spring music festivals. Contemporary Management Research, 11(1), 33-53.

Light, D. (1996). Characteristics of the audience for "events" at a heritage site. Tourism Management, 17(3), $183-190$.

Litvin, S. W. (2013). Festivals and special events: Making the investment. International Journal of Culture, Tourism and Hospitality Research, 7(2), 184-187.

Macdonnell, A. G. (1937). My Scotland. Plymouth, UK: William Brendon \& Son Ltd.

Mair, J., \& Duffy, M. (2015). Community events and social justice in urban growth areas. Journal of Policy Research in Tourism, Leisure and Events, 7(3), 282-298.

Mair, J., \& Frew, E. (2013). Hogmany: From Celtic history to global event. Conference proceedings, CAUTHE 2013: Tourism and global change: on the edge of something big. Christchurch, NZ: Lincoln University.

Mair, J., \& Whitford, M. (2013). An exploration of events research: Event topics, themes and emerging trends. International Journal of Event and Festival Management, 4(1), 6-30.

Malhotra, N. K., \& Birks, D. F. (2007). Marketing research, an applied approach. Essex, UK: Pearson Education Limited.

Mason, C. W. (2007). The Glengarry Highland Games, 1948-2003: Problematizing the role of tourism, Scottish cultural institutions, and the cultivation of nostalgia in the construction of identities. International Journal of Canadian Studies, 35, 13-38.

Mayfield, T. L., \& Compton, J. L. (1995). Development of an instrument for identifying community reasons for staging a festival. Journal of Travel Research, 37-44. 
McCleary, K. W. (1995). Applying internal marketing techniques for better festival organisation and management. Festival Management \& Event Tourism, 3(1), 1-7.

McCombie Smith, W. (1891). The athletes and athletic sports of Scotland, including bagpipe playing and dancing. Paisley, Scotland: Alexander Gardner.

McIntosh, G. (2008). The Lonach Highlanders; anthology of Lonach ways and bygone days. West Aberdeenshire, UK: Author.

McNeill, F. M. (1959). A calendar of Scottish national festivals, Candlemas to harvest home (Silver Bough series, vol. 2). Glasgow, Scotland: William MacLellan \& Co., Ltd.

McNeill, F. M. (1968). The local festivals of Scotland (Silver Bough series, vol. 4). Glasgow, Scotland: William MacLellan \& Co., Ltd.

Mohan, G., \& Mohan, J. (2002). Placing social capital. Progress in Human Geography, 26(2), 191-210.

O'Sullivan, D., \& Jackson, M. J. (2002). Festival tourism: A contributor to sustainable local economic development? Journal of Sustainable Tourism, 10(4), 325-342.

O’Sullivan, D., Pickernell, D., Senyard, J., \& Keast, R. (2008). The roles of festivals and special events in rural areas: The Welsh experience. Journal of Rural Enterprise and Management, 4(2), 44-61.

Page, S. J., \& Connell, J. (2012). Introduction. In S. J. Page \& J. Connell (Eds.), The Routledge handbook of events (pp. 1-23). Oxon, UK: Routledge.

Patterson, B. (2012). Turakina's Highland Games: Maintaining a Gaelic tradition? Immigrants \& Minorities, 30(1), 98-117.

Pegg, S., \& Patterson, I. (2010). Rethinking music festivals as a staged event: Gaining insights from understanding visitor motivations and the experiences they seek. Journal of Convention \& Event Tourism, 11(2), 85-99.

Phipps, P. (2010). Performances of power: Indigenous cultural festivals as globally engaged cultural strategy. Alternatives, 35(3), 217-240.

Portes, A. (1998). Social capital: Its origins and applications in modern sociology. Annual Review of Sociology, 24, $1-24$

Putman, R. D. (1993). The prosperous community: Social capital and public life. The American Prospect, 4(13), 35-42.

Pyke, S., Hartwell, H., Blake, A., \& Hemingway, A. (2016). Exploring well-being as a tourism product resource. Tourism Management, 55, 94-105.

Ray, C. (2001). Highland heritage: Scottish Americans in the American South. Chapel Hill, NC: The University of North Carolina Press.

Redmond, G. (1982). The sporting Scots of nineteenth century Canada. London, UK: Associated University Presses Ltd.

Rigney, A. (2011). Embodied communities: Commemorating Robert Burns. Representations, 115, 71-101.

Ritchie, J., \& Spencer, L. (2002). Qualitative data analysis for applied research. In A. M. Huberman \& M. B. Miles
(Eds.), The qualitative researcher's companion (pp. 305331). London, UK: Sage Publications Ltd.

Rogers, P., \& Anastasiadou, C. (2011). Community involvement in festivals: Exploring ways of increasing local participation. Event Management, 15, 387-399.

Ruting, B., \& Li, J. (2011). Tartans, kilts and bagpipes: Cultural identity and community creation at the Bundanoon is Brigadoon Scottish Festival. In C. Gibson \& J. Connell (Eds.), Festival places, revitalising rural Australia (pp. 265-279). Bristol, UK: Channel View Publications.

Schofield, P., \& Thompson, K. (2007). Visitor motivation, satisfaction and behavioural intention: The 2005 Naadam festival, Ulaanbaatar. International Journal of Tourism Research, 9, 329-344.

Seippel, Ø. (2012). Sport and social capital. Acta Sociologica, 49(2), 169-183.

Sharpley, R., \& Stone, P. R. (2012). Socio-cultural impacts of events: Meanings, authorized transgression and social capital. In S. J. Page \& J. Connell (Eds.), The Routledge handbook of events (pp. 347-361) Oxon, UK: Routledge.

Silverman, D. (2006). Doing qualitative research. London, UK: SAGE Publications Limited

Taylor, P. (Ed.). (2011). Torkildsen's sport and leisure management (6th ed.). Oxon, UK: Routledge.

Thompson, K., \& Schofield, P. (2009). Segmenting and profiling visitors to the Ulnaanbaatar Nadam festival by motivation. Event Management, 13, 1-15.

Tonts, M. (2005). Competitive sport and social capital in rural Australia. Journal of Rural Studies, 21, 137-149.

Torche, F., \& Valenzuela, E. (2011). Trust and reciprocity: A theoretical distinction of the sources of social capital. European Journal of Social Theory, 14(2), 181-198.

Torkildsen, G. (2005). Leisure and Recreation Management (5th ed.). Oxon, UK: Routledge.

Tranter, N. (1998). Sport, economy and society in Britain 1750-1914. Cambridge, UK: Cambridge University Press.

Tranter, N. L. (1987). Popular sports and the industrial revolution in Scotland: The evidence of the statistical accounts. The International Journal of the History of Sport, 4(1), 21-38.

Tranter, N. L. (1989). The patronage of organised sport in central Scotland, 1820-1900. Journal of Sport History, 3, 227-247.

Veal, A. J. (2011). Research methods for leisure \& tourism: A practical guide (4th ed.). Essex, UK: Pearson Education Limited.

Webster, D. (1973). Scottish Highland Games. Edinburgh, Scotland: Macdonald Printers (Edinburgh) Limited.

Webster, D. (2011). The world history of Highland Games. Edinburgh, Scotland: Luath Press Limited.

Whitford, M., \& Dunn, A. (2014). Papua New Guinea's indigenous cultural festivals: Cultural tragedy or triumph. Event Management, 18, 265-283.

Wood, E. H. (2005). Measuring the economic and social impacts of local authority events. The International Journal of Public Sector Management, 18(1), 37-53. 
Wood, E. H., \& Kenyon, A. J. (2018). Remembering together: The importance of shared emotional memory in event experiences. Event Management, 22, 163-181.

Zakus, D., Skinner, J., \& Edwards, A. (2009). Social capital in Australian sport. Sport in Society: Cultures, Commerce, Media, Politics, 12(7), 986-998.

Zarnowski, F. (2005). All around men, heroes of a forgotten sport. Oxford, UK: Scarecrow Press Inc.
Ziakas, V. (2013). A multidimensional investigation of a regional event portfolio: Advancing theory and praxis. Event Management, 17, 27-48.

Ziakas, V., \& Costa, C. A. (2010). "Between theatre and sport" in a rural event: Evolving unity and community development from the inside-out. Journal of Sport \& Tourism, 15(1), 7-26. 